\title{
Morphology of the superior gluteal nerve: a study in adult human cadavers
}

\author{
Ray B, D’ Souza AS, Saxena A, Nayak D, Sushma RK, Shetty P, Pugazhendi B \\ Department of Anatomy, Kasturba Medical College, Manipal, Karnataka. biswabina@yahoo.co.in
}

\begin{abstract}
The superior gluteal nerve (SGN) arises from the sacral plexus and enters the gluteal region above the piriformis where it divides into superior and an inferior branches. Former ends in the gluteus medius and occasionally gluteus minimus whereas latter supplies gluteus medius and minimus and ends in tensor fascia latae. Variations, relations, branching pattern and length of the SGN were reported in earlier studies. The present study was conducted to establish preliminary data on the length and branching pattern of the SGN and its relations with the neighbouring bony landmarks. Twenty two lower extremities were examined in 22 male and 13 female formalin fixed cadavers. Tip of the greater trochanter was determined as the point of reference. Statistical analysis was done using student's $T$ test. Present study will help orthopedicians performing total hip replacement through lateral and transgluteal approaches (Tab. 3, Fig. 4, Ref. 19). Full Text in PDF www.elis.sk. Key words: superior gluteal nerve, greater sciatic foramen, greater trochanter, piriformis, gluteus medius, gluteus minimus, tensor fascia latae.
\end{abstract}

The superior gluteal nerve (SGN) arises from the sacral plexus by the dorsal divisions of ventral rami of fourth, fifth lumbar and first sacral nerves (1). It is formed within the pelvis and emerges out through the greater sciatic foramen (GSF) above the piriformis. It divides into superior and inferior branches in its further course. The superior branch ends in the gluteus medius and occasionally in the gluteus minimus. The inferior branch supplies the gluteus medius and minimus and ends in the tensor fascia latae.

There are various conditions which cause pain in the hip area like arthritis, bursitis, tendonitis and fractures. Surgical treatment of arthritis of the hip joint has dramatically modified in the past decade. With the advent of surgical reconstructive techniques, the pathological conditions return to near normal in few months. In the surgical approaches, splitting and reflecting forward the anterior part of the gluteus medius and the vastus lateralis is performed as a single sheet to reattach subsequently to the greater trochanter. Most often complications in aforementioned procedures are due to the damage of blood vessels, nerves or secondary complications like infections. If the splitting of the gluteus medius is more than a few centimeter superior to the tip of the greater trochanter then the SGN and the superior gluteal vessels are at risk and it may lead to positive Trendelenburg sign with lurching gait (2).

Incidence of physical damage to the SGN depends largely on its course and branching pattern (Khan and Knowles, 2007). Several authors have reported about its distance from the greater trochanter and the safe area for the SGN during approaches to the hip joint (4-14).

Department of Anatomy, Kasturba Medical College, Manipal, Karnataka Address of correspondence: B. Ray, Dr, Department of Anatomy, AIIMS Bhopal, Saket Nagar, Bhopal, Madhya Pradesh
Objective of the present study was to establish preliminary data on the length, branching pattern, relations of the SGN with its neighboring bony landmarks.

\section{Materials and methods}

A morphometric study was carried out on 35 lower extremities of 22 male and 13 female adult cadavers, perfusion fixed in embalming fluid containing $10 \%$ formaldehyde. Gluteal regions were dissected in cadavers for the SGN and its branches. The tip of the greater trochanter (tGT) was identified (point A in Fig. 1). The point

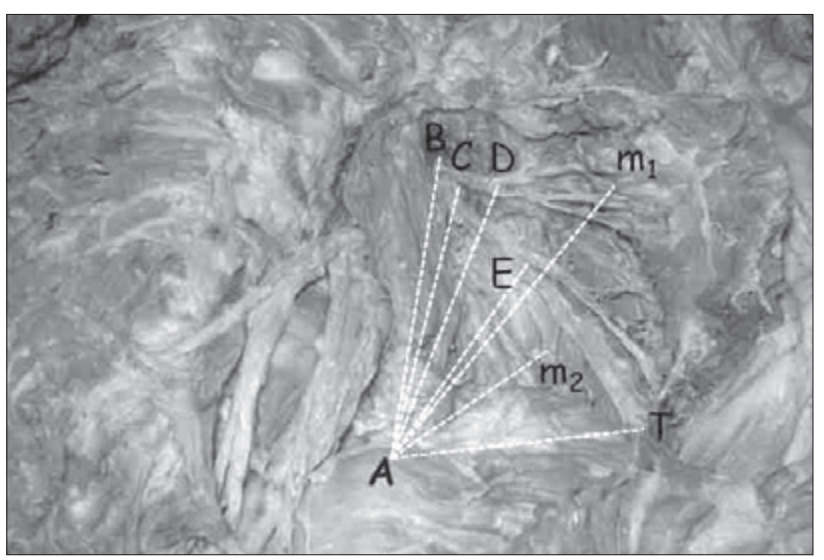

Fig. 1. Schematic illustration showing the distance from the tip of the greater trochanter till the point of emergence of nerve (AB), length of the stem (BC), length of its superior and inferior division (CD and $\mathrm{CE}$ ), from the tip of the greater trochanter to the initial branching of the superior (AD) and inferior (AE) branch of the nerve, distance from tGT to point of termination of each branch supplying muscles named gluteus medius, gluteus minimus and tensor fascia lata (Am1, Am2, AT respectively). 
$409-412$

of emergence of the nerve at GSF above the piriformis was marked (point B in Fig. 1). The SGN was traced throughout until its termination. The distance from the point of emergence of the nerve at GSF to tGT (BA), length of the stem (BC), length of its superior (CD) and inferior division (CE) were measured. The distances from the tGT to the branching points of the superior (AD) and inferior (AE) divisions of the nerve, and the points where they pierced the gluteus medius $\left(\mathrm{Am}_{1}\right)$, gluteus minimus $\left(\mathrm{Am}_{2}\right)$ and tensor fascia lata (AT) were also measured. The measurements were done using digital caliper.

Student's T test was applied to observe the differences between two sexes and the level of significance was set to $p<0.05$.

Minimum distance from the tGT to the inferior most branch of the SGN with reference to gluteus medius was measured at (a) the anterior third, (b) the middle third, and (c) the posterior third of the gluteus medius (Fig. 2).

\section{Results}

There was statistically significant outcome between genders with respect to these parameter was observed ( $>0.05$ ) (Tab. 1).

In the present study mean stem length was $1.34 \pm 0.59 \mathrm{~cm}$. Only in one case the division took place $2.7 \mathrm{~cm}$. above upper border of the piriformis and number of divisions was 2 in all cases (Tab. 1). Minimum distance between $\mathrm{tGT}$ and the inferior most branch of the SGN was $4.19 \mathrm{~cm}$ with reference to gluteus medius measured at the the middle third of the gluteus medius in a female cadaver (Tab. 2).

The number of twigs supplying the gluteus medius from the superior branch of the SGN varied between 1 and 4. Similar number of twigs were observed from the inferior division supplying the gluteus minimus. Branches reaching the tensor fascia latae from its inferior division in 17 cadavers also varied between 1 and 4 . In the remaining 5 cadavers, the tensor fascia latae received its nerve supply from superior division (Tab. 3).

Though in 21 cadavers, superior branch passed above its inferior branch (Fig. 3), in one of the specimens, the superior branch crossed below its inferior division. It descended laterally to enter the substance of the tensor fascia latae (Fig. 4).

\section{Discussion}

We investigated the length and branching pattern of the SGN. Foster et al reported the average distance between the tGT to the

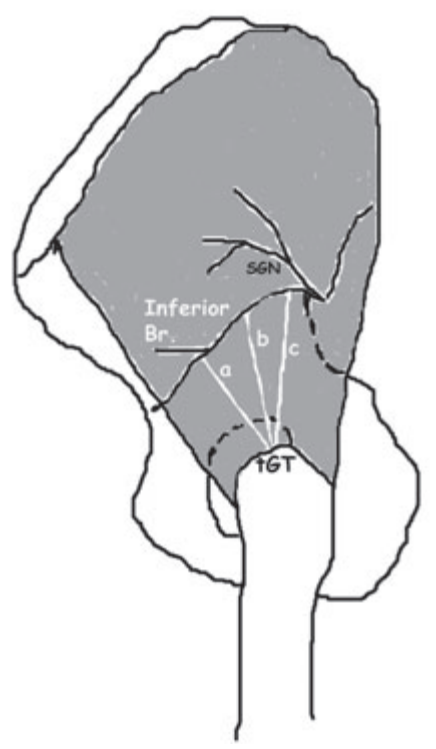

Fig. 2. Minimum distance from tGT to inferior most branch (Inferior Br.) of SGN with reference to gluteus medius was measured at (a) the anterior third, (b) the middle third, and (c) the posterior third of the gluteus medius.

emergence of the nerve as $7.82 \mathrm{~cm}$ (15). Present findings were consistent with Foster et al, the distance being $7.26 \pm 1.65 \mathrm{~cm}$ (Tab. 1). Differences between the two sexes and sides were statistically not significant in this study.

DeHart et al reported an incidence of physical damage to the SGN during hip surgery (15). According to Pérez and his coworkers, injury to the nerve results in severe complications during hip replacement surgery. They proposed a safe area $2-3 \mathrm{~cm}$ above the greater trochanter in order to prevent nerve damage (11, 14). Kenny et al stated on the basis of a cadaveric study that the physical damage to the nerve is rare and depends largely on its branching pattern (16).

Tab. 2. Distance between tGT and the inferior most branch of the SGN.

\begin{tabular}{lcc}
\hline $\begin{array}{l}\text { Minimum distance from tGT to inferior most } \\
\text { branch of SGN with reference to gluteus } \\
\text { medius }(\mathrm{cm})\end{array}$ & Male & Female \\
\hline Anterior $1 / 3$ & 5.98 & \\
Middle $1 / 3$ & 6.09 & 4.28 \\
Posterior $1 / 3$ & 6.59 & 4.48 \\
\hline
\end{tabular}

Tab. 1. Statistically significant outcome between genders with respect to these parameter.

\begin{tabular}{|c|c|c|c|c|}
\hline Parameters measured & $\begin{array}{l}\text { Mean Value with } \\
* \text { SD in male }(\mathrm{cm})\end{array}$ & $\begin{array}{l}\text { Mean value with } \\
\text { SD in female }(\mathrm{cm})\end{array}$ & $\begin{array}{l}\text { Total mean value } \\
\text { with SD }\end{array}$ & $\mathrm{p}$ value \\
\hline Distance from tGT till the point of emergence of SGN & $7.35 \pm 1.8$ & $6.76 \pm 1.67$ & $7.26 \pm 1.65$ & $\mathrm{p}>0.05$ \\
\hline Length of stem & $1.28 \pm 0.39$ & $1.42 \pm 0.85$ & $1.34 \pm 0.59$ & $\mathrm{p}>0.05$ \\
\hline Dist of tGT to branching of SGN & 6.90 & 4.94 & 6.46 & $\mathrm{p}>0.05$ \\
\hline Length of superior division & $6.68 \pm 1.50$ & $6.92 \pm 2$ & $6.78 \pm 1.63$ & $\mathrm{p}>0.05$ \\
\hline Length of inferior division & $6.4 \pm 1.45$ & $6.75 \pm 1.89$ & $6.57 \pm 1.56$ & $\mathrm{p}>0.05$ \\
\hline From tGT to initial branching of superior division & $6.73 \pm 1.28$ & $5.83 \pm 1.65$ & $6.52 \pm 1.35$ & $\mathrm{p}>0.05$ \\
\hline $\mathrm{Am}_{1}$ & $7.54 \pm 1.51$ & $6.53 \pm 2.37$ & $7.27 \pm 1.81$ & $\mathrm{p}>0.05$ \\
\hline $\mathrm{Am}_{2}$ & $6.11 \pm 1.22$ & $5.12 \pm 0.49$ & $5.98 \pm 0.94$ & $\mathrm{p}>0.05$ \\
\hline $\mathrm{AT}^{2}$ & $7.79 \pm 1.3$ & $7.79 \pm 1.92$ & $7.79 \pm 1.49$ & $\mathrm{p}>0.05$ \\
\hline
\end{tabular}




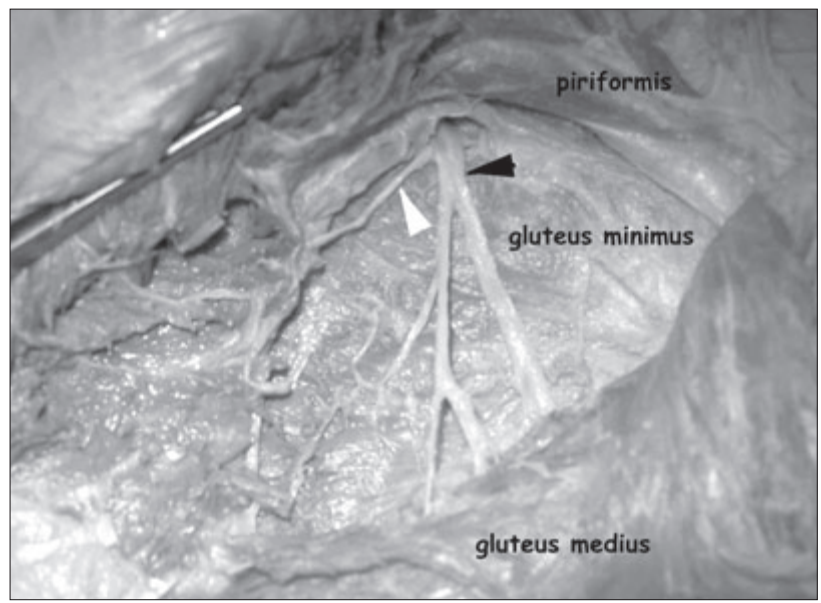

Fig. 3. Picture showing the superior (white arrowhead) and inferior (black arrowhead) branches of the SGN above the piriformis. Former ends in the gluteus medius whereas the latter supplies both gluteus medius and minimus.

Zhang et al reported variations in the branching pattern of the SGN. They observed the division of the SGN into 3 branches 2 $\mathrm{cm}$ beyond the upper border of piriformis. In the other cases, the nerve had 2-3 branches within $2 \mathrm{~cm}$ from the upper border of piriformis (17). In the present study, the SGN divided into 2 branches in every case within a distance of $2 \mathrm{~cm}$ (mean $1.34 \pm 0.59 \mathrm{~cm}$ ) from the upper border of piriformis except in one where it divided at a distance of $2.7 \mathrm{~cm}$.

In a simulated anterolateral muscle sparing minimally invasive total hip arthroplasty surgery, injury to the inferior branch of the SGN was observed by Zhang et al (2008). In their study, the distance between the anterior tubercle of the greater trochanter and the inferior branch of the SGN was $60-88 \mathrm{~mm}$. Therefore, they proposed that the gluteus medius should not to be detached for more than $6 \mathrm{~cm}$ from its anterior border to avoid nerve injury (17). We observed the distance of the tGT to branching point of the inferior division to be $5.82 \pm 1.76 \mathrm{~cm}$. Several authors investigated reliability of the safe area, which is to prevent injury to the SGN

Tab. 3. Tensor fascia latae received its nerve supply from superior division.

\begin{tabular}{llcl}
\hline Muscles & $\begin{array}{l}\text { Branche(s) } \\
\text { of SGN } \\
\text { terminating } \\
\text { in muscle }\end{array}$ & $\begin{array}{l}\text { Number of } \\
\text { branches that } \\
\text { terminate in } \\
\text { muscle }\end{array}$ & $\begin{array}{l}\text { Branches observed } \\
\text { in number of } \\
\text { cadaveric } \\
\text { specimen(s) }\end{array}$ \\
\hline Gluteus medius & superior & 1 & 2 \\
& & 2 & 19 \\
Gluteus minimus & Inferior & 4 & 9 \\
& & 1 & 5 \\
\hline Tensor fascia & Superior and & 2 & 4 \\
latae & inferior & 3 & 11 \\
& & 2 & 6 \\
& & 3 & 6 \\
& & 4 & 13 \\
\hline
\end{tabular}

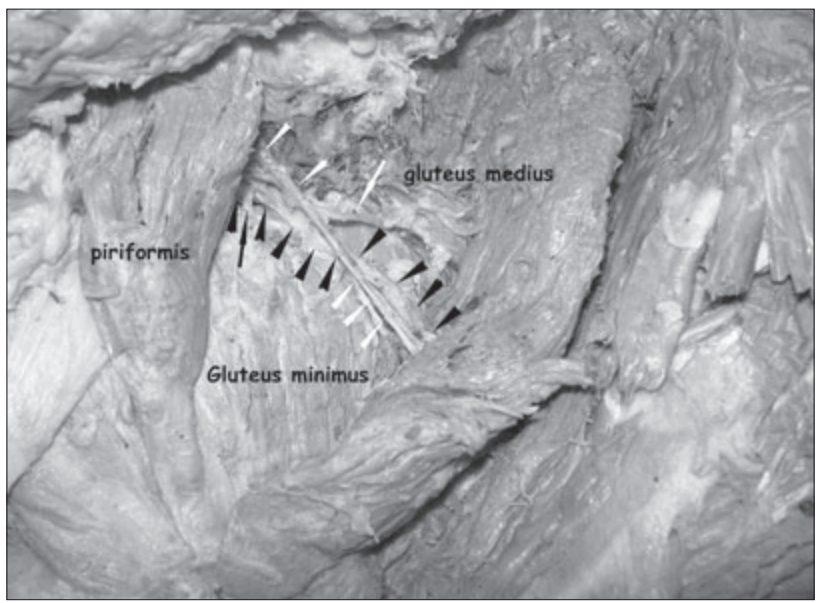

Fig. 4. Picture showing the course of superior branch of the SGN (white arrowheads) below its inferior branch (black arrowheads), descending inferolaterally and finally entering into the substance of tensor fascia latae. Branches supplying gluteus medius (white arrow) and gluteus minimus (black arrow) are also observed.

during lateral approach to the hip. Jacobs and Buxton reported the safe area of the gluteus medius muscle was upto a distance of $5 \mathrm{~cm}$ above the greater trochanter. Therefore, any surgical incision within this distance would minimize the risk of damage to the SGN and its branches (5). Eksioglu noted the distance between the point of entry of the SGN into the gluteus medius muscle and the greater trochanter and found the SGN within the safe area. Hence they questioned the reliability of the safe area as the risk of damage to the SGN may be higher in the direct lateral approach to the hip (10).

Ince et al proposed a smaller safe area for the SGN than previously reported. During minimal direct lateral approach to the hip the inferior branches within the gluteal medius are at risk and in minimal anterolateral approach to the hip, branches of the SGN to the tensor fasciae latae muscle may get affected (18). Lavigne and Loriot de Rouvray defined a safe area, which is $7 \mathrm{~cm}$ above and behind the greater trochanter, $5 \mathrm{~cm}$ above its posterior angle and $3 \mathrm{~cm}$ above its anterior angle. During the anterior transgluteal approach, dislocation of the head of the femur could tear the intramuscular nerve filaments of the gluteus medius. The more anteriorly placed branches could be compressed by retractors in acetabular exposure. On the contrary, the posterior transgluteal approach was safer for the branches of the SGN (6). Distance between the inferior branch of the SGN and the greater trochanter was reported to be in the range of $3-5 \mathrm{~cm}$ by various authors $(7-9,13)$. Ikeuchi et al stated that a $3-\mathrm{cm}$ safe zone above the tGT although is appropriate during transgluteal approach to the hip in total hip arthroplasty mostly for dysplastic hips, could be reduced in severely dysplastic ones (19). On the contrary, Khan and Knowles reported that the safe area does not exist during direct lateral approach to the hip (3). In the present study, distance between the tGT and the inferior most branch of SGN was $4.19 \mathrm{~cm}$ (Tab. 2).

In a study conducted by Jacobs et al the number of branches supplying the gluteus medius ranged between 4 and 10 (5). In the present study, the number of twigs supplying the gluteus medius, gluteus minimus and tensor fascia latae were between 1and 4 for each muscle (Tab. 3). 
$409-412$

As stated before, a unique variation was also observed in the present study, which showed the course of the superior branch of the SGN traversing beneath its inferior branch. This branch descended inferolaterally to enter into the substance of tensor fascia latae and encroaching into the safe area (Fig. 4).

The abductor muscle weakness due to injury of the SGN is found to be common in patients with total hip replacement which would cause a positive Trendlenberg sign. There is an increased probability of injury to the SGN when surgery is performed without a clear knowledge of its variable course. Therefore, a sound knowledge of the SGN is mandatory during hip related surgeries.

\section{References}

1. Standring et al. Gray's Anatomy (40th ed.). London: Churchill Livingstone, 2005: 1397-1549.

2. Fatih E, Murad U, Eftal G, Sahap AO, Ibrahim T. Reliability of the safe area for the superior gluteal nerve. Clin Orthop Relat Res 2003; 412: $111-116$.

3. Khan T, Knowles D. Damage to the superior gluteal nerve during the direct lateral approach to the hip: a cadaveric study. J Arthroplasty 2007; 22: $1198-2000$.

4. Foster DE, Hunter JR. The direct lateral approach to the hip for arthroplasty: advantages and complications. Orthopedics 1987; 10: 274-280.

5. Jacobs LGH, Buxton RA. The course of the superior gluteal nerve in the lateral approach to the hip. J Bone Joint Surg Am 1989; 71: 1239-1243.

6. Lavigne P, Loriot de Rouvray TH. The superior gluteal nerve. Anatomical study of its extrapelvic portion and surgical resolution by trans-gluteal approach. Rev Chir Orthop Reparatrice Appar Mot 1994; 80: 188-195.

7. Comstock C, Imrie S, Goodman SB. A clinical and radiographic study of the safe area using the direct lateral approach for total hip arthroplasty. J Arthroplasty 1994; 94 (9): 527-531.

8. Ozsoy MH, Basarir K, Bayramoglu A, Erdemli B, Tuccar E, Eksioglu MF. Risk of superior gluteal nerve and gluteus medius muscle injury during femoral nail insertion. J Bone Joint Surg Am 2007; 89: 829-834.
9. Bos JC, Stoeckart R, Klooswijk AI, van Linge B, Bahadoer R. The surgical anatomy of the superior gluteal nerve and anatomical radiologic bases of the direct lateral approach to the hip. Surg Radiol Anat 1994; 16: 253-258.

10. Eksioglu F, Uslu M, Gudemez E, Atik OS, Tekdemir I. Reliability of the safe area for the superior gluteal nerve. Clin Orthop Relat Res 2003; 412: 111-116.

11. Pérez MM, Llusá M, Ortiz JC. Superior gluteal nerve: safe area in hip surgery. Surg Radiol Anat 2004; 26: 225-229.

12. Collinge C, Coons D, Aschenbrenner J. Risks to the superior gluteal neurovascular bundle during percutaneous iliosacral screw insertion. An anatomical cadaver study. J Orthop Trauma 2005; 19: 96-101.

13. Basarir K, Ozsoy MH, Erdemli B, Bayramoglu A, Tuccar E, Dincel VE. The safe distance for the superior gluteal nerve in direct lateral approach to the hip and its relation with the femoral length. A cadaver study. Arch Orthop Trauma Surg 2008; 128: 645-650.

14. Miguel-Pérez M, Ortiz-Sagristà JC, López I, Pérez-Bellmunt A, Llusá M, Alex L, Combalia A. How to avoid injuries of the superior gluteal nerve. Hip Int 2010; 20 (Suppl 7): 26-31.

15. DeHart MM, Riley LH. Nerve injuries in total hip arthroplasty. J Am Acad Orthop Surg 199; 7: 101-111.

16. Kenny P, O'Brien CP, Synnott K, Walsh MG. Damage to the superior gluteal nerve after two different approaches to the hip. J Bone Joint Surg Br 1999; 81-B: 979-981.

17. Zhang XL, Shen H, Qin XL, Wang Q. Anterolateral muscle sparing approach total hip arthroplasty: an anatomic and clinical study. Chin Med J (Engl) 2008; 121 (15): 1358-1363.

18. Ince A, Kemper M, Waschke J, Hendrich C. Minimally invasive anterolateral approach to the hip. Risk to the superior gluteal nerve. Acta Orthop 2007; 78: 86-89.

19. Ikeuchi M, Kawakami T, Yamanaka N, Okanoue Y, Tani T. Safe zone for the superior gluteal nerve in the transgluteal approach to the dysplastic hip. Intraoperative evaluation using a nerve stimulator. Acta Orthopaedica 2006; 77: 603-606. 